Acta Crystallographica Section D

Biological

Crystallography

ISSN 0907-4449

Martin R. Singleton, Michail N. Isupov and Jennifer A. Littlechild*

Departments of Chemistry and Biological Sciences, University of Exeter, Stocker Road, Exeter EX4 4QD, England

Correspondence e-mail: j.a.littlechild@ex.ac.uk

\title{
Crystallization and preliminary X-ray diffraction studies of pyrrolidone carboxyl peptidase from the hyperthermophilic archaeon Thermococcus litoralis
}

\begin{abstract}
Pyrrolidone carboxyl peptidase from the hyperthermophilic archaeon Thermococcus litoralis has been crystallized in a form suitable for $\mathrm{X}$-ray diffraction from ammonium sulfate or ammonium dihydrogen orthophosphate using the vapour-phase diffusion method. Crystals from both precipitants are of the orthorhombic space group $P 2_{1} 2_{1} 2$ with unit-cell dimensions $a=94.06, b=149.06, c=73.54 \AA$. A complete data set to $2.8 \AA$ resolution has been collected from crystals grown from ammonium sulfate
\end{abstract}

Received 15 August 1997 Accepted 26 November 1998

\section{Introduction}

Pyrrolidone carboxyl peptidases (pcps; E.C. 3.4.19.3) catalyse the hydrolysis of aminoterminal pyroglutamate residues from peptides and proteins (Doolittle \& Armentrout, 1968). They form a subgroup of the large aminopeptidase family of enzymes which demonstrate a wide range of substrate specificity and catalytic mechanisms (Gonzales \& RobertBaudouy, 1994). Pcps have been identified in mammalian and plant species (Szewczuk \& Kwiatkowska, 1970), as well as from a variety of bacterial sources (Awadé et al., 1992).

Mechanistically, pcps have been divided into two groups: cysteine peptidases and metallopeptidases. The former group includes all the bacterial enzymes studied so far and one class of mammalian enzyme. The other class of mammalian enzyme is a zinc-containing metallopeptidase and has been shown to regulate the activity of the neuropeptide, thyrotropin-releasing hormone.

The bacterial pcps are the most extensively studied, with $p c p$ genes being cloned from the bacteria Pseudomonas fluorescens (Gonzales \& Robert-Baudouy, 1994), Bacillus subtilis (Awadé et al., 1992), Bacillus amyloliquefaciens (Yoshimoto et al., 1993), Streptococcus pyogenes (Cleuziat et al., 1992) and Staphylococcus aureus (Patti et al., 1995). The enzymes have been biochemically characterized and are either homodimers or tetramers with subunit molecular weights between 22 and $30 \mathrm{kDa}$. They possess high sequence homology; however, they show no similarity to any other type of peptidase and the pcps are therefore thought to constitute a distinct class of enzyme (Cleuziat et al., 1992). A common feature of all these sequences is the totally conserved cysteine- and histidine-containing motifs, which are proposed to be catalytic residues, as in the cysteine proteases exemplified by papain
(Polgar, 1973). Inhibition studies (Sullivan et al., 1977) and site-directed mutagenesis experiments (Yoshimoto et al., 1993) support this hypothesis. A third, acidic residue has recently been proposed to stabilize the imidazolium ring of the histidine during catalysis in an analogous manner to the serine protease triad, although the exact sequence position of this residue has not been established (Lesaux et al., 1996).

The pyrrolidone carboxyl peptidase from the anaerobic hyperthermophile Thermococcus litoralis has recently been cloned and overexpressed in Escherichia coli (Singleton et $a l$., unpublished data). The enzyme shows high sequence homology to the bacterial pcps and has a similar quaternary structure of $4 \times$ $24 \mathrm{kDa}$ subunits. In addition, the protein shows the extreme thermotolerance exhibited by enzymes derived from such sources, with a half-life of more than $0.5 \mathrm{~h}$ at $363 \mathrm{~K}$. Structural investigations should help to further understand the mechanism of these enzymes and provide some insights into the property of protein thermostability. Here, we describe the crystallization of the enzyme in a form suitable for high-resolution X-ray studies.

\section{Experimental}

The pcp gene from Thermococcus litoralis strain NS-C was isolated and overexpressed in E. coli as described previously (Singleton et al., unpublished data). For crystallization, the protein was concentrated to $10 \mathrm{ml}^{-1}$ in $50 \mathrm{mM}$ potassium phosphate $\mathrm{pH} 7.5,10 \mathrm{~m} M$ DTT by ultrafiltration using Centricon 10 concentrators (Amicon) in the same buffer, and crystallization trials were set up using the hangingdrop vapour-diffusion method. Initial screening was carried out with the sparsematrix conditions described by Jancarik \& Kim 
Table 1

Data-collection statistics.

\begin{tabular}{llllrl}
\hline $\begin{array}{l}\text { Resolution } \\
\text { shell }(\AA)\end{array}$ & $\begin{array}{l}\text { Number of } \\
\text { reflections }\end{array}$ & $\begin{array}{l}\text { Complete- } \\
\text { ness (\%) }\end{array}$ & $R_{\text {sym }}^{\dagger}$ & $I / \sigma(I)$ & $\begin{array}{l}I>2 \sigma \\
(\%)\end{array}$ \\
\hline 5.94 & 2882 & 96.42 & 0.075 & 18.13 & 86.0 \\
4.72 & 5646 & 97.08 & 0.096 & 10.27 & 84.4 \\
4.12 & 8323 & 96.87 & 0.094 & 9.32 & 86.9 \\
3.75 & 10942 & 96.18 & 0.138 & 6.16 & 79.3 \\
3.48 & 13526 & 95.87 & 0.203 & 4.25 & 70.5 \\
3.27 & 16093 & 95.51 & 0.241 & 3.43 & 64.1 \\
3.11 & 18681 & 95.27 & 0.312 & 2.53 & 53.8 \\
2.98 & 21139 & 94.70 & 0.361 & 2.17 & 48.7 \\
2.86 & 22766 & 90.90 & 0.340 & 2.05 & 46.7 \\
\hline
\end{tabular}

$\dagger R_{\text {sym }}=\left(\sum|I-\langle I\rangle|\right) / \sum I$, where $I$ is the observed intensity and $\langle I\rangle$ is the average intensity of symmetry-related reflections.

(1991) using a Crystal Screen kit (Hampton Research, Laguna Hills, CA) in addition to a range of ammonium sulfate concentrations.

Diffraction studies were carried out using a Siemens Hi-Star area detector with graphite-monochromated $\mathrm{Cu} K \alpha$ radiation from a Siemens rotating-anode generator operating at $50 \mathrm{kV}$ and $100 \mathrm{~mA}$. Frames were indexed and processed using the programs FRAMBO and SAINT (Siemens Industrial Automation, Inc.).

\section{Results and discussion}

Needle-shaped crystals of dimensions $0.8 \times$ $0.1 \times 0.05 \mathrm{~mm}$ grew from $1 M$ ammonium dihydrogen orthophosphate, $0.1 M$ citrate pH 5.6 in approximately two weeks. Crystals of similar morphology but with larger dimensions $(0.5 \times 0.1 \times 0.1 \mathrm{~mm})$ also grew from $35 \%$ ammonium sulfate, $50 \mathrm{mM}$ potassium phosphate $\mathrm{pH}$ 7.5. By reducing the reservoir buffer to $\mathrm{pH}$ 6.5, still larger crystals of 1.0 $\times 0.3 \times 0.15 \mathrm{~mm}$ could be grown. X-ray analysis showed crystals from both precipitants to have identical cell dimensions and space group, so the larger crystals grown from ammonium sulfate were used for all further work.

These crystals showed diffraction to $2.7 \AA$, with weak reflections visible at $2.1 \AA$ on the rotating-anode generator. The unit cell was determined to be orthorhombic with refined lattice dimensions of $a=95.06, b=150.06, c$ $=73.54 \AA$. An examination of systematic absences indicated space group $P 22_{1} 2_{1} 2$. This allows two or four subunits per asymmetric unit. Assuming four subunits gives a Matthews coefficient of $2.73 \AA^{3} \mathrm{Da}^{-1}$ and a solvent content of $55 \%$, while two subunits give values of $5.46 \AA^{3} \mathrm{Da}^{-1}$ and $77 \%$ for the Matthews coefficient and solvent content, respectively, which are extreme values for a water-soluble protein (Matthews, 1968). Thus, it is most likely that the asymmetric unit contains one tetramer of the enzyme.

A complete data set was collected at room temperature using $0.2^{\circ}$ frames comprising 49152 observations merging to 23309 unique reflections with an overall $R_{\text {sym }}=$ $11.2 \%$. Some statistics of the data collection are shown in Table 1.
The crystals have been shown to diffract to beyond $1.8 \AA$ resolution on station 9.5 of the Daresbury Synchrotron Radiation Source, and a search for suitable heavy-atom derivatives for phasing purposes is currently in progress.

MRS and MNI are supported by grants from the Biotechnology and Biological Sciences Research Council. MRS is a CASE student with Chiroscience Ltd, Cambridge, UK.

\section{References}

Awadé, A., Cleuziat, P., Gonzales, T. \& RobertBaudouy, J. (1992). FEBS Lett. 305, 67-73.

Cleuziat, P., Awadé, A. \& Robert-Baudouy, J. (1992). Mol. Microbiol. 6, 2051-2063.

Doolittle, R. F. \& Armentrout, R. W. (1968). Biochemistry, 7, 516-521.

Gonzales, T. \& Robert-Baudouy, J. (1994). J. Bacteriol. 176, 2569-2576.

Jancarik, J. \& Kim, S.-H. (1991). J. Appl. Cryst. 24, 409-411.

Lesaux, O., Gonzales, T. \& Robert-Baudouy, J. (1996). J. Bacteriol. 178, 3308-3313.

Matthews, B. W. (1968). J. Mol. Biol. 33, 491-497.

Patti, J. M., Schneider, A., Garza, N. \& Boles, J. O. (1995). Gene, 166, 95-99.

Polgar, L. (1973). Eur. J. Biochem. 33, 104-109.

Sullivan, J. J., Muchnicky, E. E., Davidson, B. E. \& Jago, G. R. (1977). Aust. J. Biol. Sci. 30, $543-$ 552.

Szewczuk, A. \& Kwiatkowska, J. (1970). Eur. J. Biochem. 8, 63-67.

Yoshimoto, T., Shimoda, T., Kitazono, A., Kabashima, T., Ito, K. \& Tsuru, D. (1993). J. Biochem. 113, 67-73. 